\title{
openheart 2019 Italian Society of Cardiology Census on telemedicine in cardiovascular disease: a report from the working group on telecardiology and informatics
}

\author{
Natale Daniele Brunetti (D) , ${ }^{1}$ Giuseppe Molinari, ${ }^{2}$ Flavio Acquistapace, ${ }^{3}$ \\ Tecla Zimotti, ${ }^{1}$ Gianfranco Parati, ${ }^{4,5}$ Ciro Indolfi, ${ }^{6}$ Francesco Fedele, ${ }^{7}$ \\ Stefano Carugo ${ }^{8}$
}

\begin{abstract}
- Additional material is published online only. To view please visit the journal online (http://dx.doi.org/10.1136/ openhrt-2019-001157).
\end{abstract}

To cite: Brunetti ND, Molinari G, Acquistapace F, et al. 2019 Italian Society of Cardiology Census on telemedicine in cardiovascular disease: a report from the working group on telecardiology and informatics. Open Heart 2020;7:e001157. doi:10.1136/ openhrt-2019-001157

Received 20 August 2019 Revised 21 December 2019 Accepted 17 February 2020

Check for updates

(C) Author(s) (or their employer(s)) 2020. Re-use permitted under CC BY-NC. No commercial re-use. See rights and permissions. Published by BMJ.

For numbered affiliations see end of article.

Correspondence to

Prof Natale Daniele Brunetti; nd. brunetti@unifg.it

\section{ABSTRACT}

Background The aim of this study was to assess by a census supported by the Italian Society of Cardiology (Società Italiana di Cardiologia, SIC) the present implementation of telemedicine in the field of cardiovascular disease in Italy.

Methods A dedicated questionnaire was sent by email to all the members of the SIC: data on telemedicine providers, service provided, reimbursement, funding and organisational solutions were collected and analysed. Results Reported telemedicine activities were mostly stable and public hospital based, focused on acute cardiovascular disease and prehospital triage of suspected acute myocardial infarction (prehospital ECG, always interpreted by a cardiologist and not automatically reported by computerised algorithms). Private companies delivering telemedicine services in cardiology (ECGs, ambulatory ECG monitoring) were also present. In 16\% of cases, ECGs were also delivered through pharmacies or general practitioners. ICD/CRT-D remote control was performed in $42 \%$ of cases, heart failure patient remote monitoring in 37\% (21\% vital parameters monitoring, 32\% nurse telephone monitoring). Telemedicine service was public in $74 \%$ of cases, paid by the patient in $26 \%$. About half of telemedicine service received no funding, $17 \%$ received State and/or European Union funding. Conclusions Several telemedicine activities have been reported for the management of acute and chronic cardiovascular disease in Italy. The whole continuum of cardiovascular disease is covered by telemedicine solutions. A periodic census may be useful to assess the implementation of guidelines recommendations on telemedicine.

\section{INTRODUCTION}

Telemedicine support can be applied and allow dramatic improvements in the management of the whole continuum of cardiovascular disease. ${ }^{1}$ On the base of solid evidence, guidelines and position papers recommend

\section{Key questions}

What is already known about this subject?

- Telemedicine may improve the effectiveness of care in several fields of medicine.

What does this study add?

- A partial description of telemedicine activities presently implemented in Italy for prevention and care of cardiovascular disease is provided.

How might this impact on clinical practice?

- The present report may provide data for the planning of future interventions and the coordination of current activities.

the implementation of telemedicine solutions for the care of acute and chronic cardiovascular disease. ${ }^{23}$

Despite such robust evidence supporting the use of telemedicine in cardiology, clear and detailed assessments of implemented telemedicine activities in real-world scenarios are lacking and information about telemedicine in Italian cardiology is quite poor. A snapshot of telemedicine implementation, instead, could be extremely useful in disseminating successful experiences in the closer areas, reducing the time of implementation and costs, concentrating funding, resources and efforts.

The aim of this study was, therefore, to assess by a census supported by the Italian Society of Cardiology (Società Italiana di Cardiologia, SIC) the present implementation of telemedicine in the field of cardiovascular disease nowadays in Italy.

\section{METHODS}

A dedicated questionnaire was sent by email to all the members of the SIC with an invitation 


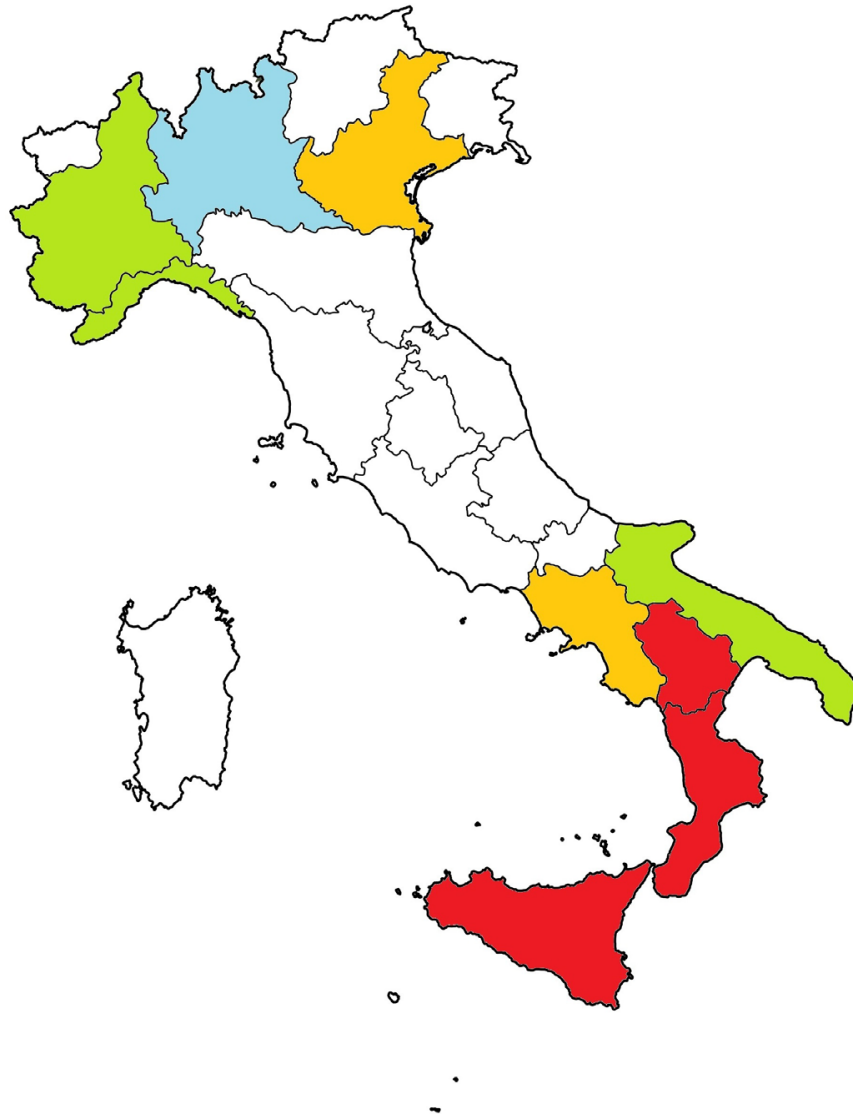

Figure 1 Map of reported telemedicine activities in cardiovascular disease: red, one; orange, two; green, three; cyan, four.

to answer all the fields included in the questionnaire, to be sent back by mail. SIC members represent about one third of 7500 cardiologists of the Italian Federation of Cardiology, a European Society of Cardiology country member. A reminder was 3 months later sent to all nonrespondents. The anonymity of responders and participants in the census was granted by double blinding data gathering from statistical analysis. Double responding from the same institution was checked and corrected before statistical analysis. Continuous variables were reported as mean $\pm \mathrm{SD}$, dichotomic as percentages.

The Working Group on Telecardiology and Informatics of the SIC supported and managed the census, collected and analysed the data and questionnaires.

\section{Questionnaire}

The study questionnaire was made up of 22 questions, some open and some other multiple-choice questions. The first seven questions were general questions on age, gender and job position of the reporting SIC member. The second group of the question was oriented to describe the institution where the telemedicine programme was held (dimension of hospital provider, public/private provider). The following group of questions was aimed at describing the telemedicine programme (prehospital/ in-hospital/posthospital, area of cardiovascular disease, kind of cardiology service provided and number of
Table 1 Telemedicine provider's characteristics

\begin{tabular}{ll}
\hline Variable & \\
\hline Hospital institution & \\
$\quad$ Hub hospital & $81 \%$ \\
\hline University hospital & $47 \%$ \\
Research foundation hospital & $16 \%$ \\
Hospital ownership & \\
Public hospital & $74 \%$ \\
Private hospital & $16 \%$ \\
\hline Private non-hospital companies & $10 \%$ \\
\hline
\end{tabular}

teleconsultations provided per week) and a final group enquired about source of funding.

A copy of the questionnaire is provided in the appendix section (online supplementary figure S1).

\section{RESULTS}

A total of 2400 cardiologists SIC members were invited by mail to participate in the census. Eighteen activities reported were sufficiently described to be included in the census. Most of the telecardiology activities were reported from northern and southern regions of Italy (mostly Liguria, Piedmont, Lombardy and Apulia, figure 1).

All responders were cardiologists, $79 \%$ were men, mean age was 51 years with a meaningful experience in cardiology of 19 years. The reporter activity was hospital based in $95 \%$ of cases, from hospital with a mean number of $580 \pm 415$ beds, in $81 \%$ of cases a cardiology hub, mostly a public hospital (74\%) (table 1).

The telemedicine activity was in $88 \%$ of cases, not an experimental programme but an institutional activity, dating from on average $7 \pm 5$ years. About mean 1000 patients were supported by telemedicine per week per institution $(1081 \pm 450)$.

Telemedicine service was public in $74 \%$ of cases, partly reimbursed by the national healthcare system in $69 \%$, paid by the patient in $25 \%$ (figure 2). Half of the telemedicine service $(50 \%)$ received no funding, $17 \%$ received State funding and 17\% European Union funding.

\section{Diagnostic procedures with telemedicine support}

Telemedicine service provided was in $84 \%$ of cases prehospital ECG, always interpreted by a cardiologist and not automatically reported by computerised algorithms. In $47 \%$ of cases, ECG service was delivered within providing hospitals, in $26 \%$ between hospitals, in $42 \%$ supporting an emergency room (table 2).

In $16 \%$ ECGs were delivered also through pharmacies or general practitioners; in $37 \%$ of cases an ambulatory ECG recording service was provided, in $26 \%$ accessible from pharmacies, in $16 \%$ through general practitioners. Ambulatory blood pressure monitoring was provided from pharmacies (21\%) in and general practitioners office in $16 \%$ of cases each. 


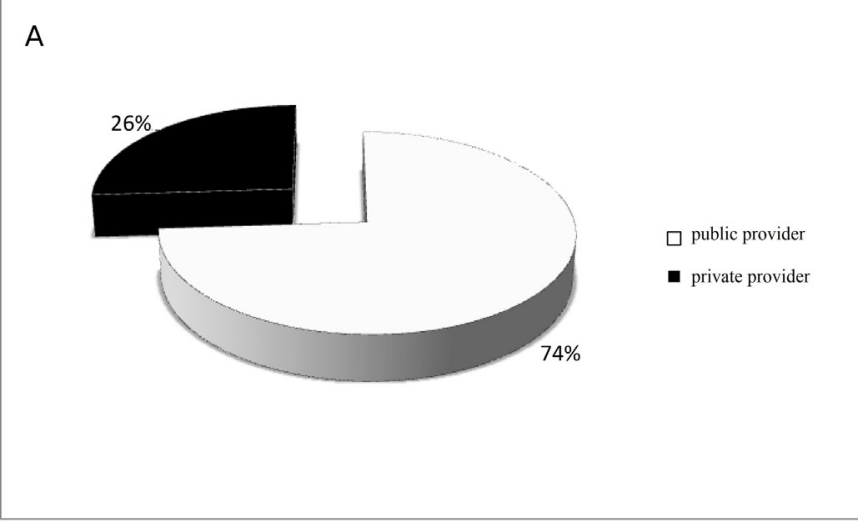

B

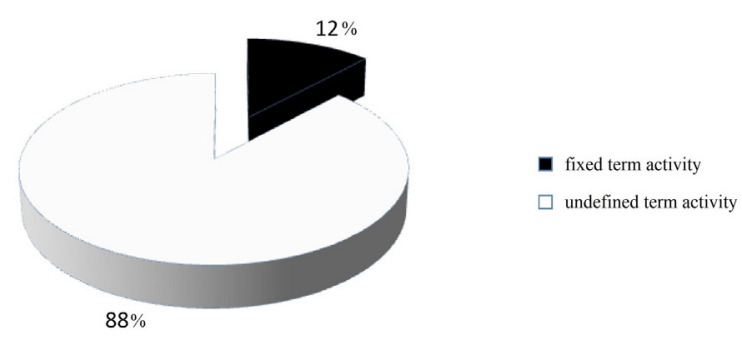

Figure 2 (A) Private or public telemedicine provider (rates). (B) Fixed or undefined term of the telemedicine activity (rates).

\section{Remote telemedicine monitoring}

ICD/CRT-D remote control was performed in $42 \%$ of cases and heart failure patient remote monitoring in $37 \%$ (21\% vital parameters monitoring, $32 \%$ nurse telephone monitoring).

\section{DISCUSSION}

This is the first general census on telemedicine services in the field of cardiovascular disease held in Italy by a national scientific society. Last similar data collections date back to 2015 (rete IMA web 2) but were mainly focused on acute myocardial infarction networks for primary coronary angioplasty. Our census is more general and seeks to collect data covering the whole continuum of cardiovascular disease. Surveys on telemedicine activities from other countries are quite rare and usually not focused on cardiovascular disease management. ${ }^{4}$

\section{Diagnostic procedures with telemedicine support}

Analysing data from this census, several observations can be drafted. First, the principal area of interest in telemedicine for cardiovascular disease is still represented by prehospital triage of acute myocardial infarction. Larger activities in this field remain an early prehospital diagnosis of ST-elevation acute myocardial infarction (STEMI) ${ }^{5}$ where a fast track referral for primary angioplasty by-passing any emergency room delay is associated

\begin{tabular}{|c|c|}
\hline \multicolumn{2}{|l|}{ Variables } \\
\hline \multicolumn{2}{|l|}{ Telemedicine programme duration } \\
\hline Fixed-term telemedicine activity & $12 \%$ \\
\hline Indefinite time telemedicine activity & $88 \%$ \\
\hline \multicolumn{2}{|l|}{ Telemedicine ECG } \\
\hline Prehospital ECG & $79 \%$ \\
\hline In-hospital telemedicine ECG & $47 \%$ \\
\hline Interhospital telemedicine ECG & $26 \%$ \\
\hline Emergency room telemedicine ECG & $42 \%$ \\
\hline Outpatients telemedicine ECG & $63 \%$ \\
\hline Telemedicine ECG through pharmacies & $16 \%$ \\
\hline Telemedicine ECG through general practitioners & $16 \%$ \\
\hline \multicolumn{2}{|l|}{ Ambulatory monitoring } \\
\hline Outpatients ECG monitoring & $37 \%$ \\
\hline Through pharmacies & $26 \%$ \\
\hline Through general practitioners & $16 \%$ \\
\hline \multicolumn{2}{|l|}{ Outpatients blood pressure monitoring } \\
\hline Through pharmacies & $21 \%$ \\
\hline Through general practitioners & $16 \%$ \\
\hline Remote heart failure monitoring & $37 \%$ \\
\hline Vital signs remote monitoring & $21 \%$ \\
\hline Telephone monitoring & $32 \%$ \\
\hline Monitoring through dedicated devices & $16 \%$ \\
\hline \multicolumn{2}{|l|}{ Telemedicine rehabilitation } \\
\hline After heart surgery & $16 \%$ \\
\hline After heart failure & $11 \%$ \\
\hline \multicolumn{2}{|l|}{ Other forms of monitoring } \\
\hline ICD/CRT-D monitoring & $42 \%$ \\
\hline Mentoring & $11 \%$ \\
\hline \multicolumn{2}{|l|}{ Reimbursement } \\
\hline Reimbursed by national healthcare system & $69 \%$ \\
\hline Paid by the patient & $25 \%$ \\
\hline \multicolumn{2}{|l|}{ Funding } \\
\hline State funding & $17 \%$ \\
\hline European Union funding & $17 \%$ \\
\hline Private funding & $11 \%$ \\
\hline No funding & $50 \%$ \\
\hline
\end{tabular}

with shorter times of reperfusion and lower mortality rates. ${ }^{6}$

Prior experiences from our same country showed lower rates of adverse outcome and complications in subjects with STEMI triaged with telemedicine ECGs. ${ }^{78}$ Telemedicine triage, therefore, represents in several Italian regions the benchmark solution for the organisation of networks for the timely treatment of acute myocardial infarction (STEMI) ${ }^{9-11}$ 


\section{Remote telemedicine monitoring}

Another group of telemedicine activities are instead dedicated to outpatients with chronic cardiovascular disease, a field where telemedicine support is useful in easily accessing cardiology examinations such as ECGs, ambulatory ECG or blood pressure monitoring. Often, telemedicine services are not directly delivered to patients with cardiovascular disease but through general practitioners taking care of such patients. The possibility of early diagnosis of cardiovascular disease, when general practitioners are remotely supported by a cardiologist through telemedicine, has been shown by several studies from Italy; telemedicine support may improve the appropriate management of chest pain suspected for acute myocardial ischaemia ${ }^{12}$ and the diagnosis of arrhythmias such as atrial fibrillation. ${ }^{14}$

Likewise, telemedicine services are often delivered through pharmacies and pharmacists. ${ }^{15}$ Clinical pharmacy telemedicine interventions in the outpatient or ambulatory setting, primarily via phone, have an overall positive impact on outcomes related to clinical disease management, patient self-management and adherence in the management of chronic diseases. ${ }^{16}$ As pharmacy services are easily accessible and widely distributed in the community setting, a maximum benefit should be expected from telemedicine interventions provided in this context. ${ }^{17}$

Usually, telemedicine services for patients with cardiovascular disease or general practitioners are delivered by private telemedicine companies.

In several cases, remote control of implantable electronic devices is delivered by telemedicine providers. In this field, despite contrasting evidence, remote control implementation could reduce the costs of management ${ }^{18}$ and allow an earlier diagnosis of implantable devices defects. Long-term home monitoring of ICD is at least as safe as standard ambulatory follow-ups with respect to a broad spectrum of major adverse events; it also lowers significantly the number of appropriate and inappropriate shocks delivered, spares the device battery ${ }^{19}$ and reduces costs. ${ }^{20}$ Remote monitoring is a safe alternative to conventional care and may significantly lower the number of ambulatory visits during the long-term follow-up of permanently paced patients. $^{21}$

Despite the second opinion by telemedicine may shorten the time to diagnosis and length of hospitalisation and significantly decreased the need for transport of infants with mild or no heart disease, ${ }^{22}$ no case of second opinion application and very few cases of telementoring have been reported in this census. There is, therefore, a large room for further improvement in this field of telemedicine.

Finally, some reported activities are focused on heart failure monitoring. Telemedicine solutions for remote control of vital parameters and nurse monitoring of subjects with heart failure were pioneering fields for telemedicine in Italy. Two models were generally applied, one based on the remote monitoring of vital signs and another on both remote monitoring of vital signs and nursing. In the HHH study, a multicentre, multicountry study, self-managed home telemonitoring of both vital signs and respiration was shown as feasible in heart failure patients, with surprisingly high compliance. ${ }^{23}$ In another study, the use of telemedicine was associated with a onethird decrease in the total number of hospital readmissions and the total number of episodes of haemodynamic instability. ${ }^{24}$ The rate of heart failure-related readmission was halved and the mean cost for hospital readmission was significantly lower.

\section{Other aspects}

Contrasting data are given on reimbursement. Most services provided by public hospitals for urgent cardiovascular disease are free, whereas ambulatory ECG and blood pressure monitoring are partly reimbursed and partly paid by the patients. In general, costs and reimbursement still represent an open question hampering the widespread implementation of telemedicine support.

Interestingly, the majority of telemedicine activities reported in this census are not experimental projects with a short time perspective but consolidated services lasting from several years. The slow transformation of telemedicine from an occasional, spotty, here and there approach into stable cardiology assistance regularly provided witnesses with the attention paid nowadays by a cardiologist to telemedicine technologies and the wide acknowledgement of benefit achievable through telemedicine.

The relatively limited participation to this census, however, raises the doubt that several telecardiology activities may have been missed by this census and that the issue of telemedicine in the management of cardiovascular disease still not represents a real priority for several cardiologists. Differences in regional healthcare systems and rules, despite evidence of the cost-effectiveness of telemedicine solutions even from Italy, ${ }^{25}$ surely do not facilitate the huge implementation of telemedicine solutions. Stable initiatives aimed at continuous monitoring of telemedicine in the field of cardiovascular disease and its further implementation are surely warranted.

\section{CONCLUSIONS}

Several telemedicine activities have been reported for the management of acute and chronic cardiovascular diseases in Italy. The whole continuum of cardiovascular disease is covered by telemedicine solutions. A periodic census may be useful to assess the implementation of guidelines recommendations on telemedicine.

\section{Limitations}

Despite significant number of Italian cardiologists members of the SIC, not all activities in the field of telecardiology may have been reported, partly because of medium bias (invitation letter sent by mail), partly because of respondent bias (not all cardiologists contacted may have been willing to answer the form) and 
partly because of knowledge gap (not all activities in the field of telecardiology may have been known to contacted cardiologists).

Data reported in the received forms have not been controlled by data analysts; errors and unfounded data may be not completely excluded.

No details have been reported on technologies and software adopted.

Provided results must be considered taking into account partiality of the data and the absence of a real national questionnaire on the argument.

\section{Author affiliations}

${ }^{1}$ Department of Medical and Surgical Sciences, Università degli Studi di Foggia,

Foggia, Puglia, Italy

${ }^{2}$ Telemedico srl, Genova, Italy

${ }^{3}$ Centro Medico Sanacare, Lugano, Ticino, Switzerland

${ }^{4}$ Università degli Studi di Milano-Bicocca, Milano, Lombardia, Italy

${ }^{5}$ Istituto Auxologico Italiano Istituto di Ricovero e Cura a Carattere Scientifico,

Milano, Lombardia, Italy

${ }^{6}$ Magna Graecia University of Catanzaro, Catanzaro, Calabria, Italy

${ }^{7}$ Sapienza University of Rome, Roma, Lazio, Italy

${ }^{8}$ Università degli Studi di Milano, Milano, Lombardia, Italy

Contributors NDB: planned and managed the study, wrote the paper and supervised the study. GM, FA and TZ: gathered the data. NDB and TZ: performed statistical analysis. GP, Cl, FF and SC: revised the paper and supervised the study.

Funding The authors have not declared a specific grant for this research from any funding agency in the public, commercial or not-for-profit sectors.

Competing interests None declared.

Patient consent for publication Not required.

Ethics approval The study complies with the Declaration of Helsinki. No ethics committee approval was required on the base of the observational nature of the study.

Provenance and peer review Not commissioned; externally peer reviewed.

Data availability statement Data are available upon reasonable request.

Open access This is an open access article distributed in accordance with the Creative Commons Attribution Non Commercial (CC BY-NC 4.0) license, which permits others to distribute, remix, adapt, build upon this work non-commercially, and license their derivative works on different terms, provided the original work is properly cited, appropriate credit is given, any changes made indicated, and the use is non-commercial. See: http://creativecommons.org/licenses/by-nc/4.0/.

\section{ORCID iD}

Natale Daniele Brunetti http://orcid.org/0000-0001-9610-7408

\section{REFERENCES}

1 Caldarola P, Gulizia MM, Gabrielli D, et al. ANMCO/SIT consensus document: telemedicine for cardiovascular emergency networks. Eur Heart J Suppl 2017;19:D229-43.

2 [2]Brunetti ND, Scalvini S, Acquistapace F, et al. Telemedicine for cardiovascular disease continuum: a position paper from the Italian Society of cardiology Working group on Telecardiology and informatics. Int J Cardiol 2015;184:452-8.

3 Beygui F, Castren M, Brunetti ND, et al. Pre-Hospital management of patients with chest pain and/or dyspnoea of cardiac origin. A position paper of the acute cardiovascular care association (ACCA) of the ESC. Eur Heart J Acute Cardiovasc Care 2020;9:2048872615604119.

4 Zachrison KS, Boggs KM, M Hayden E, et al. A national survey of telemedicine use by US emergency departments. J Telemed Telecare 2018;17:1357633X18816112.

5 Ibanez B, James S, Agewall S, et al. 2017 ESC guidelines for the management of acute myocardial infarction in patients presenting with ST-segment elevation: the task force for the management of acute myocardial infarction in patients presenting with ST-segment elevation of the European Society of cardiology (ESC). Eur Heart $J$ 2018;39:119-77.

6 Brunetti ND, De Gennaro L, Correale M, et al. Pre-Hospital electrocardiogram triage with telemedicine near halves time to treatment in STEMI: a meta-analysis and meta-regression analysis of non-randomized studies. Int J Cardiol 2017;232:5-11.

7 Brunetti ND, Bisceglia L, Dellegrottaglie G, et al. Lower mortality with pre-hospital electrocardiogram triage by telemedicine support in high risk acute myocardial infarction treated with primary angioplasty: preliminary data from the Bari-BAT public emergency medical service 118 registry. Int J Cardiol 2015;185:224-8.

8 Brunetti ND, Di Pietro G, Aquilino A, et al. Pre-Hospital electrocardiogram triage with tele-cardiology support is associated with shorter time-to-balloon and higher rates of timely reperfusion even in rural areas: data from the Bari- Barletta/Andria/Trani public emergency medical service 118 registry on primary angioplasty in ST-elevation myocardial infarction. Eur Heart J 2014;3:204-13.

9 Brunetti ND, Amodio G, De Gennaro L, et al. Telecardiology applied to a region-wide public emergency health-care service. $J$ Thromb Thrombolysis 2009;28:23-30.

10 Bisignani G, De Bonis S, Bisignani A, et al. [Telecardiology: clinical, technical and social aspects. The project of the ASP of Cosenza, Italy]. G Ital Cardiol 2016;17:959-65.

11 Ortolani P, Marzocchi A, Marrozzini C, et al. Usefulness of prehospital triage in patients with cardiogenic shock complicating ST-elevation myocardial infarction treated with primary percutaneous coronary intervention. Am J Cardiol 2007;100:787-92.

12 Molinari G, Valbusa A, Terrizzano M, et al. Nine years' experience of telecardiology in primary care. J Telemed Telecare 2004;10:249-53.

13 Molinari G, Reboa G, Frascio M, et al. The role of telecardiology in supporting the decision-making process of general practitioners during the management of patients with suspected cardiac events. $J$ Telemed Telecare 2002;8:97-101.

14 Scalvini S, Piepoli M, Zanelli E, et al. Incidence of atrial fibrillation in an Italian population followed by their GPs through a telecardiology service. Int J Cardiol 2005;98:215-20.

15 Brunetti ND, Lanzone S, Dellegrottaglie G, et al. The capital study (cardiovascular prevention with Telecardiology in ApuLia). $J$ Cardiovasc Med 2016;17:455-61.

16 Niznik JD, He H, Kane-Gill SL. Impact of clinical pharmacist services delivered via telemedicine in the outpatient or ambulatory care setting: a systematic review. Res Social Adm Pharm 2018;14:707-17.

17 Omboni S, Caserini M. Effectiveness of pharmacist's intervention in the management of cardiovascular diseases. Open Heart 2018;5:e000687.

18 Ricci RP, Vicentini A, D'Onofrio A, et al. Economic analysis of remote monitoring of cardiac implantable electronic devices: results of the health economics evaluation Registry for remote follow-up (tariff) study. Heart Rhythm 2017;14:50-7.

19 Guédon-Moreau L, Lacroix D, Sadoul N, et al. A randomized study of remote follow-up of implantable cardioverter defibrillators: safety and efficacy report of the ECOST trial. Eur Heart $J$ 2013;34:605-14.

20 Guédon-Moreau L, Lacroix D, Sadoul N, et al. Costs of remote monitoring vs. ambulatory follow-ups of implanted cardioverter defibrillators in the randomized ECOST study. Europace 2014;16:1181-8.

21 Mabo P, Victor F, Bazin P, et al. A randomized trial of long-term remote monitoring of pacemaker recipients (the COMPAS trial). Eur Heart J 2012;33:1105-11.

22 Webb CL, Waugh CL, Grigsby J, et al. Impact of telemedicine on hospital transport, length of stay, and medical outcomes in infants with suspected heart disease: a multicenter study. J Am Soc Echocardiogr 2013;26:1090-8.

23 Pinna GD, Maestri R, Andrews D, et al. Home telemonitoring of vital signs and cardiorespiratory signals in heart failure patients: system architecture and feasibility of the $\mathrm{HhH}$ model. Int $\mathrm{J}$ Cardiol 2007;120:371-9.

24 Giordano A, Scalvini S, Zanelli E, et al. Multicenter randomised trial on home-based telemanagement to prevent Hospital readmission of patients with chronic heart failure. Int J Cardiol 2009;131:192-9.

25 Brunetti ND, Dellegrottaglie G, Lopriore C, et al. Prehospital telemedicine electrocardiogram triage for a regional public emergency medical service: is it worth it? A preliminary cost analysis. Clin Cardiol 2014;37:140-5. 